\title{
How does dynamical downscaling affect model biases and future projections of explosive extratropical cyclones along North America's Atlantic coast?
}

Article

Accepted Version

Seiler, C., Zwiers, F. W., Hodges, K. I. and Scinocca, J. F. (2018) How does dynamical downscaling affect model biases and future projections of explosive extratropical cyclones along North America's Atlantic coast? Climate Dynamics, 50 (1-2). pp. 677-692. ISSN 0930-7575 doi:

https://doi.org/10.1007/s00382-017-3634-9 Available at https://centaur.reading.ac.uk/70253/

It is advisable to refer to the publisher's version if you intend to cite from the work. See Guidance on citing.

Published version at: https://link.springer.com/article/10.1007\%2Fs00382-017-3634-9

To link to this article DOI: http://dx.doi.org/10.1007/s00382-017-3634-9

Publisher: Springer

All outputs in CentAUR are protected by Intellectual Property Rights law, including copyright law. Copyright and IPR is retained by the creators or other copyright holders. Terms and conditions for use of this material are defined in the End User Agreement. 


\section{www.reading.ac.uk/centaur}

\section{CentAUR}

Central Archive at the University of Reading

Reading's research outputs online 
Noname manuscript No.

(will be inserted by the editor)

\section{How does dynamical downscaling affect model biases and future}

2 projections of explosive extratropical cyclones along North America's

\section{Atlantic coast?}

4 C. Seiler · F.W. Zwiers · K.I. Hodges · J.F. Scinocca

5 Received: October 14, 2016

6 Abstract Explosive extratropical cyclones (EETCs) are rapidly intensifying low pressure systems that generate 7 severe weather along North America's Atlantic coast. Global climate models (GCMs) tend to simulate too few 8 EETCs, which may partly be related to their coarse horizontal resolution and poorly resolved moist diabatic 9 processes. This study explores whether EETC frequency biases can be reduced through dynamical downscaling, and whether this affects climate change projections of storms along North America's Atlantic coast. A regional climate model (CanRCM4) is forced with the CanESM2 GCM for the periods 1981 to 2000 and 2081 to 2100. EETCs are tracked from relative vorticity using an objective feature tracking algorithm. CanESM2 simulates $38 \%$ fewer EETC tracks compared to reanalysis data, which is consistent with a negative Eady growth rate bias $14\left(-0.1\right.$ day $\left.^{-1}\right)$. Downscaling CanESM2 with CanRCM4 increases EETC frequency by one third, which reduces the frequency bias to $-22 \%$, and coincides with a $22 \%$ increase in maximum EETC precipitation. Anthropogenic C. Seiler

Pacific Climate Impacts Consortium, University of Victoria, Victoria, BC, Canada, University House 1, PO Box 1700 Stn CSC, University of Victoria, Victoria, BC, Canada V8W 2Y2

E-mail: cseiler@uvic.ca

F.W. Zwiers

Pacific Climate Impact Consortium, University of Victoria, Victoria, BC, Canada

\section{K.I. Hodges}

University of Reading, Reading, United Kingdom

\section{J.F. Scinocca}

Canadian Centre for Climate Modelling and Analysis, Victoria, BC, Canada 
greenhouse gas forcing is projected to decrease EETC frequency $(-15 \%,-18 \%)$ and Eady growth rate $\left(-0.2\right.$ day $^{-1}$,

-0.2 day $\left.^{-1}\right)$, and to increase maximum EETC precipitation $(46 \%, 52 \%)$ in CanESM2 and CanRCM4, respectively. The limited effect of dynamical downscaling on EETC frequency projections is consistent with the lacking impact on the maximum Eady growth rate. To conclude, the coarse spatial resolution of GCMs presents an important limitation for simulating extreme ETCs, but biases in the Eady growth rate are likely to be just as relevant.

Keywords Explosive extratropical cyclones · Dynamical downscaling · Model biases · Climate change projections

\section{Introduction}

Extratropical cyclones (ETCs) affect the general circulation through the exchange of heat, moisture, and momentum, but also impact human activity through the generation of strong surface winds, high waves, extreme precipitation, and associated hazardous conditions. Many of the most violent winter storms along North America's Atlantic coast undergo rapid intensification, with deepening rates typical of "weather bombs" (Sanders and Gyakum, 1980). These explosive ETCs (EETCs) have caused fatalities and billions of \$USD property damage (Kocin et al., 1995), and remain difficult to forecast (Edward B Carroll, personal communication, July 21, 2015). Given the severe weather conditions associated with EETCs, it is of great public interest to better understand how these events may evolve under a warming climate.

Global climate models (GCMs) reproduce the climatology of observed ETC frequency and intensity reasonably well, with a tendency to slightly underestimate both variables and to simulate tracks that are too zonal (Lambert and Fyfe, 2006; Ulbrich et al., 2008; Zappa et al., 2013a). GCMs tend to project an overall decline in ETC frequency as a response to anthropogenic greenhouse gas (GHG) forcing, with a weak polar shift in the Northern Pacific, and a downstream extension of the Atlantic storm track into Europe (Bengtsson et al., 2006; McDonald, 2011; Chang et al., 2012; Collins et al., 2013; Christensen et al., 2013). The latter implies an increase in storm frequency close to the British Isles, and a decrease in storm frequency in the Norwegian and Mediterranean Seas and subtropical central Atlantic (Zappa et al., 2013b). The precipitation rate associated with ETCs is projected to increase along North America's Atlantic coast (Zappa et al., 2013b). GCM performance in simulating EETCs is less impressive; they tend to underestimate EETC frequency by up to two thirds (Seiler and Zwiers, 2016a). The same models project a reduction in EETC frequency in the Northern Atlantic by $17 \%$ on average by the end of this century (Seiler and Zwiers, 2016b). 
Anthropogenic GHG forcing is expected to affect ETCs through multiple competing processes. This includes (i) changes in baroclinicity in the lower and upper troposphere due to polar and tropical amplification, and (ii) an increase in the atmospheric water vapor content that may intensify ETCs through enhanced latent heating (Hall et al., 1994). The latter process has been shown to be sensitive to the horizontal model resolution (Willison et al., 2013). Given the modest spatial resolution of most current GCMs, it is natural to ask if model biases could be reduced by increasing the horizontal model resolution, and whether this would affect the corresponding projections.

The impact of horizontal model resolution on ETC biases and projections can be examined in dynamical downscaling experiments, where a regional climate model (RCM) is forced with lateral boundary conditions from a GCM or reanalysis data. Previous studies show that dynamical downscaling has the potential to significantly affect model biases and projections of ETCs. Willison et al. (2013) forced the Weather Research and Forecasting model (WRF) with the NCEP global forecast system (GFS) final analysis, and compared results where WRF was run at lower $(120 \mathrm{~km})$ and higher horizontal resolutions $(20 \mathrm{~km})$ for a domain covering the North Atlantic. Using an Eulerian approach, the study showed enhancement of the positive feedback between ETC intensification and latent heat release at the higher resolution, resulting in a systematic increase in eddy intensity and a stronger storm track. These results are consistent with findings from Long et al. (2009), who downscaled the Canadian Climate Centre model (CGCM2) with the Canadian Regional Climate Model (CRCM version 3.5) for the Northwest Atlantic and eastern North America. Using a Lagrangian approach in which storms were tracked from $6 \mathrm{~h}$ mean sea level pressure (MSLP) minima, dynamical downscaling was found to increase the frequency of strong ETCs with MSLP < $995 \mathrm{hPa}$ along North America's Atlantic coast. However, it remains unclear whether this is a response of the ETC or of the background MSLP field. Contrary findings are presented in Colle et al. (2015) who downscaled reanalysis data (NCEP-CFSR) with six different RCMs for North America's Atlantic coast and detected a 5-10\% decrease in ETCs tracked from $850 \mathrm{hPa}$ relative vorticity. Côté et al. (2015) related similar findings to the presence of the regional model boundary in the vicinity of the storm track.

Downscaling may also significantly affect climate change projections of ETC frequencies and intensities. Willison et al. (2015) conducted a pseudo-global warming experiment where projected changes in temperature from five GCMs were applied to reanalysis data, which was then used as the initial and lateral boundary conditions in a regional climate model experiment for a selection of days with storms. The study finds that changes in temperature increases storm activity in the northeastern Atlantic, and that this is further enhanced when increasing the model 
resolution from a $120-\mathrm{km}$ to a $20-\mathrm{km}$ grid spacing. Long et al. (2009) on the other hand finds that downscaling enhances the reduction in ETC frequency projected by a global model (CGCM2) in the Northwest Atlantic and eastern North America by 10\%. Such contrary findings may result from differences in the experimental design and methods employed. Also, it remains unclear to what degree the impacts of dynamical downscaling are affected by differences in physical parameterizations used in the global models compared to the regional models.

The studies outlined above show that dynamical downscaling has the potential to significantly affect model ETC biases and projections. The enhanced condensational heating in the high-resolution model runs may play an important role in this context. Only a few studies have assessed the impacts of dynamical downscaling on ETC biases and projections, and their conclusions remain ambiguous. While pseudo-global warming experiments are suitable for exploring mechanisms in controlled experiments (Marciano et al., 2015), the number of tracks that are simulated in such studies is too small to assess the statistical significance of the projected changes. Finally, a focus on EETCs is to our knowledge still missing, despite their potential for severe impacts, and the important role that latent heating can play in rapid intensification (Fink et al., 2012).

This study assesses how dynamical downscaling affects model biases and projections of EETCs along North America's Atlantic coast. This is of particular relevance for our previous work on EETC biases and projections of a multi GCM ensemble (Seiler and Zwiers, 2016a,b). Special attention is paid to the use of different spatial filters required to compute storm tracks from different horizontal grids in a consistent manner that allows intercomparison of results. Section 2 presents our data and approach used for identifying and tracking EETCs in global and regional climate model data from seven experiments. Section 3 assesses biases and projections of all ETCs and of EETCs simulated by the Canadian Earth System Model (CanESM2) and the Canadian Regional Climate Model (CanRCM4). Both models are compatible as they share the exact same physics package. The role of baroclinic instability for EETC biases and projections is explored as well. Section 4 elaborates on the principal findings and discusses opportunities for future research on the competing processes that determine storm biases and projections.

\section{Methods}

\subsection{Data}

We use global data from the ERA-Interim reanalysis (Dee et al., 2011) and the Canadian Earth System Model (CanESM2, Arora et al., 2011). ERA-Interim is produced by the European Centre for Medium-Range Weather Forecasts (ECMWF). The atmospheric component is a spectral model with T255 truncation and 60 vertical levels, 
and the data are converted to a $480 \times 240\left(0.75^{\circ}, 83 \mathrm{~km}\right)$ horizontal linear grid. CanESM2 is developed by the Canadian Centre for Climate Modelling and Analysis (CCCma) and participated in the fifth phase of the Coupled Model Intercomparison Project (CMIP5). Its atmospheric component has spectral T63 resolution with 35 vertical levels with a lid near $1 \mathrm{hPa}$, and the data are converted to a $128 \times 64\left(2.8125^{\circ}, 313 \mathrm{~km}\right)$ horizontal linear grid. The CanESM2 simulation (r1i1p1) uses "all" forcings for the historical period ending in 2005 (greenhouse gases, other anthropogenic forcings, solar and volcanic) and follows the Representative Concentration Pathway 8.5 emissions scenario for 2006-2100 (RCP8.5) (Taylor et al., 2012).

CanESM2 is dynamically downscaled to a horizontal resolution of $0.22^{\circ}(24 \mathrm{~km})$ with the Canadian Regional Climate Model (CanRCM4) (Scinocca et al., 2016). CanRCM4 is a hydrostatic model with a hybrid vertical coordinate system and a regular latitude-longitude grid with rotated pole. Vertical model levels match those in CanESM2, except that CanRCM4 has a lower model lid located at $13 \mathrm{hPa}$. Sea surface temperatures and sea ice extent in CanRCM4 are prescribed by the forcing data. CanESM2 and CanRCM4 are compatible, as they share the same physics package and parameter settings of physical parametrizations. The employed cloud microphysics scheme of both models treat condensation as an instantaneous adjustment of the thermodynamic properties to equilibrium (von Salzen et al., 2013). Spectral nudging is applied to the horizontal wind fields from the model top down to $850 \mathrm{hPa}$ and to temperature in the top three vertical levels of the model domain. The regional model grid is similar to that of the Coordinated Regional Climate Downscaling Experiment (CORDEX) North America experiment (Giorgi et al., 2009), with the difference that it extends further into the Atlantic to include storm tracks that affect North America's coastal region (NAE22 grid, hereafter) (Figure 1).

Variables used for ETC tracking include 6 hourly zonal and meridional wind components at $850 \mathrm{hPa}$, and 6h MSLP. Baroclinic instability is quantified from daily mean values of zonal and meridional wind components, geopotential height, air temperature, and specific humidity at $850 \mathrm{hPa}$ and $500 \mathrm{hPa}$. Finally, we also use daily precipitation in order to assess the hydrological component of EETCs. Our data covers the historical period from 1981 to 2000 and the projected high emission scenario RCP8.5 from 2081 to 2100.

2.2 Cyclone tracking

ETCs are identified using the objective feature tracking algorithm TRACK (Hodges, 1994; Hodges et al., 1995; Hodges, 1999). The algorithm computes relative vorticity from the horizontal wind velocity at $850 \mathrm{hPa}$ at the resolution of the input data. We spatially filter relative vorticity to T42 resolution prior to tracking in all cases 
to ensure that results from data sources with different horizontal resolutions are comparable. This is achieved through spherical harmonic decomposition in the case of global data (Anderson et al., 2003), and by discrete cosine transform for dynamically downscaled data (Denis et al., 2002). The large scale background is removed by setting the coefficients in the spectral transform expansion for total wave-numbers $<5$ to zero in the global filtering and the equivalent for the discrete cosine transform. Feature points are detected based on local extreme values. The algorithm computes tracks by determining the correspondence between feature points for adjacent time steps. Tracks are first initialized using a nearest neighbor method and then refined by minimizing a cost function, in spherical geometry, for track smoothness subject to adaptive constraints to produce the optimal set of smoothest tracks. Post-tracking filters are applied to retain only storms that have a relative vorticity greater than $10^{-5} \mathrm{~s}^{-1}$, that last longer than two days, and that travel further than $1000 \mathrm{~km}$.

MSLP values are assigned to each ETC center by searching for the closest T42 MSLP minimum to the location of the relative vorticity maxima within a great circle radius of $5^{\circ}$. T42 MSLP is used rather than the full resolution MSLP to ensure that results from data sources with different horizontal resolutions are comparable. Deepening rates are computed for each time step by comparing the MSLP values that belong to the same track and that are $24 \mathrm{~h}$ apart. EETCs are identified as ETCs with deepening rates greater than or equal to one bergeron $(b)$ (Sanders and Gyakum, 1980):

$$
b=\frac{24 h P a}{24 h o u r s} \frac{\sin (\theta)}{\sin (60)},
$$

where $\theta$ is the latitude of the ETC center. The pressure drop between two cyclone centers is scaled according to the latitude of the second cyclone center. EETC maximum wind speed and maximum precipitation are computed by finding the highest T42 wind speed and precipitation within a $6^{\circ}$ radius around each ETC center. Daily precipitation values are assigned to each six hourly ETC center for the day that the ETC center is occurring. As for MSLP, T42 values rather than full resolution values are used. The projected increase in maximum EETC precipitation is compared to the projected increase in monthly mean near surface air temperature from October to March, which is averaged over the coastal region enclosed by the polygon depicted in Figure 1.

\subsection{Experiments}

The impacts of dynamical downscaling on model biases and projections of EETC frequency and intensity are assessed by comparing results from seven experiments (Table 1). The first three experiments consist of ETC 
tracks that are computed from global grids, where relative vorticity is spatially filtered to T42 resolution through spherical harmonic decomposition (SH). This includes tracks from ERA-Interim and from CanESM2 for the historical (H) period 1981-2000 (ERAH-SH and GCMH-SH, respectively), and for the future period (F) 20812100 under RCP8.5 forcing (GCMF-SH). The remaining four experiments consist of ETC tracks that are computed from the NAE22 grid with relative vorticity spatially filtered to T42 equivalent resolution through discrete cosine transform (DC). This applies to ERA-Interim (ERAH-DC) and the historical experiment of CanESM2 (GCMHDC), which are spatially interpolated to the NAE22 grid by bilinear interpolation, as well as to the historical and projected simulation of CanRCM4 forced with CanESM2 (RCMH-DC and RCMF-DC, respectively). ETC statistics are computed for the North American Atlantic coast enclosed by the inner polygon depicted in Figure 1.

The impacts of dynamical downscaling on model biases and projections are quantified by comparing runs that are based on the same grid extension and spatial filter (Table 1). This separates the effects of dynamical downscaling from the potential impacts of a limited model domain and the use of different grid types and associated spatial filtering techniques.

Model biases in CanESM2 are assessed by contrasting results from GCMH-SH against ERAH-SH. To gain insight into how spatial filtering affects the bias we compare results from GCMH-DC against ERAH-DC. The impact of dynamical downscaling is quantified by comparing RCMH-DC against GCMH-DC, and the effects on model biases are determined by comparing RCMH-DC against ERAH-DC. Finally, we assess whether dynamical downscalling alters climate change projections by comparing the projected changes from GCMF-SH and GCMHSH against RCMF-DC and RCMH-DC.

\subsection{Clausius-Clapeyron relation}

The projected change in maximum EETC precipitation per degree warming is compared to the projected change in the saturation vapor pressure $\left(e_{s}\right)$ per degree warming. The warming is quantified from the climatological mean cold season (October to March) near-surface air temperature averaged over the polygon that encloses North America's Atlantic coast (Figure 1). The saturation vapor pressure is estimated from near-surface air temperature following the Clausius-Clapeyron equation (Stull, 2000):

$$
e_{s}=e_{0} \exp \left[\frac{L_{v}}{R_{v}}\left(\frac{1}{T_{0}}-\frac{1}{T}\right)\right]
$$


where $N$ is the static stability, or Brunt-Väisälä frequency (Stull, 2000):

$$
N=\sqrt{\frac{g}{T_{v}}\left(\frac{\partial T_{v}}{\partial z}+\Gamma_{d}\right)},
$$

with

$$
T_{v}=T(1+0.61 r)
$$

and

$$
r=q /(1-q)
$$

where $f$ is the Coriolis parameter, $\mathbf{v}$ is the horizontal wind velocity, $z$ is the geopotential height, $g$ is the gravitational acceleration, $\Gamma_{d}$ is the dry adiabatic lapse rate, $T_{v}$ is the virtual temperature, $T$ is the air temperature, $r$ is the water vapor mixing ratio, and $q$ is the specific humidity. The Eady growth rate is computed for daily values between 850 and $500 \mathrm{hPa}$, and is then averaged for each month. The partial derivatives with respect to $z$ are approximated by computing the differences between the two pressure levels. Our analysis of the Eady growth rate considers the months October to March, as most EETCs occur during the cold season (Seiler and Zwiers, 2016a). Also, we focus on North America's Atlantic coast, a major region of EETC genesis related to the presence of the Gulf Stream (Roebber, 1984). 


\section{Results}

\subsection{All extratropical cyclones}

Looking at all ETCs along North America's Atlantic coast shows that storms in GCMH-SH tend to be too weak compared to ERAH-SH, leading to overestimation of weaker ETCs with maximum vorticities below $610^{-5}$ $\mathrm{s}^{-1}$, and too few stronger ETCs above this threshold (GCMH-SH minus ERAH-SH) (Figure 2a and c). The absolute negative bias is largest for strong ETCs that reach vorticities of about $1010^{-5} \mathrm{~s}^{-1}$. The relative negative bias becomes larger as relative vorticity increases, reaching $76 \%$ for ETCs with maximum vorticities of $1210^{-5}$ $\mathrm{s}^{-1}$ (Figure 2e). This is consistent with findings from Zappa et al. (2013a) who showed that CMIP5 models generally underestimate the frequency of extreme ETCs. Regridding data to NAE22 prior to ETC tracking yields similar but not identical values (GCMH-DC minus ERAH-DC) (Figure 2b, c and e). The impact of using two different grids and spatial filtering techniques is sufficiently small to yield comparable results. Nevertheless it is necessary to restrict comparisons to data sets that are based on the same grid and spatial filtering technique as the results are not identical. Downscaling CanESM2 with CanRCM4 decreases the frequency bias of stronger ETCs with vorticities ranging from 6 to $1310^{-5} \mathrm{~s}^{-1}$ (RCMH-DC minus ERAH-DC) (Figure 2c). This is consistent with Long et al. (2009), who also found that dynamical downscaling can increase the frequency of strong ETCs along North America's Atlantic coast.

Anthropogenic GHG forcing is projected to generally weaken ETCs, leading to more events with vorticities below $510^{-5} \mathrm{~s}^{-1}$ and fewer events with vorticities between 5 and $1110^{-5} \mathrm{~s}^{-1}$ (GCMF-SH minus GCMH-SH) (Figure 2a, $\mathrm{d}$ and $\mathrm{f}$ ). The total number of tracks decreases by $2 \%$, but changes are not statistically significant. This agrees with results from Christensen et al. (2013) who found only a weak reduction of ETC frequency for the CMIP5 climate model ensemble in the same region. Extreme ETCs with relative vorticity exceeding $1110^{-5} \mathrm{~s}^{-1}\left(99 \mathrm{th}^{\mathrm{h}}\right.$ percentile) on the other hand are projected to increase, rising from 79 tracks to 97 tracks per 20-year period (23\%; not statistically significant). Dynamical downscaling further reduces the projected number of ETC tracks with vorticities between 4 and $910^{-5} \mathrm{~s}^{-1}$ (RCMF-DC minus RCMH-DC) (Figure 2d).

To summarize, CanESM2 tends to simulate too many weak and not enough strong ETCs. Dynamical downscaling reduces this bias by increasing the number of stronger storms. Anthropogenic GHG forcing is projected to weaken ETCs, leading to more weak storms and fewer strong events. Dynamical downscaling further reduces 
the number of strong storms. The total number of ETCs, and the frequency of extreme ETCs (99th percentile) is not projected to change significantly.

3.2 Explosive extratropical cyclones

\subsubsection{Frequency}

The most intense ETCs that pass along North America's Atlantic coast undergo rapid intensification (Figure 2a, magenta-colored bars). The annual mean EETC frequency is 45 tracks for ERAH-SH (Figure 3a). GCMHSH underestimates this number by $38 \%$, or 17 EETC tracks per year (Table 2), which is consistent with the negative frequency bias of stronger ETCs documented in section 3.1. Comparable EETC frequency biases are also found for other CMIP5 models (Seiler and Zwiers, 2016a). Regridding the same data to the NAE22 grid prior to tracking leads to similar results, with 40 tracks for ERAH-DC, and 24 tracks for GCMH-DC, and a negative EETC frequency bias of $41 \%$ (17 tracks per year). The slightly lower frequencies for data that are interpolated to the NAE22 grid are consistent with a loss of information that can be expected through the regridding process and somewhat different filtering approach that must be used in non-global domains. Nevertheless, as for ETCs in general, we conclude that the impact of using two different grids and spatial filtering techniques is sufficiently small to yield comparable results, but that comparisons should be restricted to data sets that are based on the same grid and spatial filtering technique as the results are not identical.

Dynamical downscaling increases EETC track frequency by 33\% (8 tracks per year) when comparing RCMHDC against GCMH-DC (Table 2, Figure 3a, and Figure 4). Downscaling therefore reduces the frequency bias from $-41 \%$ in the global data on the NAE22 grid (GCMH-DC minus ERAH-DC) to $-22 \%$ (RCMH-DC minus ERAH-DC), which is consistent with the increase in stronger ETCs in the downscaled solution documented in section 3.1.

CanESM2 projects a decrease in EETC frequency of 15\% (4 tracks $\left.\mathrm{yr}^{-1}\right)($ GCMF-SH minus GCMH-SH) (Table 2, Figure 3a). This agrees with the projected decrease in stronger ETCs shown in section 3.1, and is comparable to the reduction in the Northern Atlantic (-17\%) found for the CMIP5 climate model ensemble (Seiler and Zwiers,

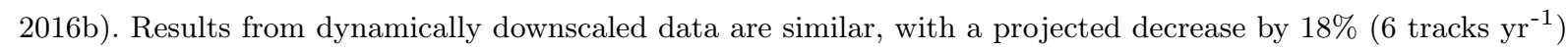
(RCMF-DC minus RCMH-DC). This result is in agreement with findings from Long et al. (2009) but is in contrast to results from Willison et al. (2015) for reasons discussed in section 4 . 
To summarize, CanESM2 underestimates the frequency of EETCs by $38 \%$, and dynamical downscaling reduces this bias to $-22 \%$. The projected relative reduction in EETC frequency is similar for the global model (-15\%) and its dynamically downscaled counterpart (-18\%).

\subsubsection{Intensity}

The average EETC track along North America's Atlantic coast has a maximum relative vorticity of $810^{-5} \mathrm{~s}^{-1}$, a minimum MSLP of $981 \mathrm{hPa}$, a maximum deepening rate of $21 \mathrm{hPa} 24 \mathrm{~h}^{-1}$, a maximum wind speed of $36 \mathrm{~m} \mathrm{~s}^{-1}(130$ $\mathrm{km} \mathrm{h}^{-1}$ ), and a maximum precipitation rate of $33 \mathrm{~mm}_{\text {day }}{ }^{-1}$ (ERAH-SH) (Figure 3b-f). Intensities computed from GCMH-SH are similar, with slightly lower values in maximum relative vorticity $\left(-0.810^{-5} \mathrm{~s}^{-1},-9 \%\right)$, maximum wind speed $\left(-2 \mathrm{~m} \mathrm{~s}^{-1},-5 \%\right)$, and maximum precipitation $\left(-2.8 \mathrm{~mm} \mathrm{day}^{-1},-8 \%\right)$, and slightly higher values in minimum MSLP (5 hPa, 0.5\%) (Table 2, Figure 3b-f). Regridding the data to the NAE22 grid prior to tracking has no major impacts on EETC intensities. The biases of GCMH-SH and GCMH-DC differ by $0.3610^{-5} \mathrm{~s}^{-1}(5 \%)$ for relative vorticity, $1 \mathrm{hPa}(0.07 \%)$ for MSLP, $1 \mathrm{~m} \mathrm{~s}^{-1}(2 \%)$ for wind speed, and $1 \mathrm{~mm}$ day $^{-1}(3 \%)$ for maximum precipitation.

Dynamical downscaling increases maximum EETC precipitation by $22 \%\left(7 \mathrm{~mm}\right.$ day $\left.^{-1}\right)($ RCMH-DC minus GCMH-DC) (Table 2, Figure 3f). This is consistent with the increase in EETC frequency described in section 3.2.1, and indicates that the frequency increase is linked to an enhanced positive feedback between ETC intensification and latent heat release at the higher resolution as suggested by Willison et al. (2013). EETC relative vorticity, MSLP, deepening rate, and wind speed are not significantly affected by dynamical downscaling (Table 2).

Anthropogenic GHG forcing is projected to increase maximum EETC precipitation by $46 \%$, or by $14 \mathrm{~mm}$ day $^{-1}$ (GCMF-SH minus GCMH-SH) (Table 2, Figure 3f). This is consistent with findings from Zappa et al. (2013b) who show that CMIP5 models project an increase in the frequency of ETCs that are associated with strong precipitation in the Northern Atlantic. The projected increase in EETC precipitation is consistent with a projected $35 \%$ increase in specific humidity at $850 \mathrm{hPa}$ from October to March (not shown). The maximum EETC precipitation increase per degree warming is $8.9 \% \mathrm{~K}^{-1}$, which exceeds the Clausius-Clapeyron rate of $6.6 \% \mathrm{~K}^{-1}$ for the region (Table 3). While maximum wind speed is projected to increase by $1.4 \mathrm{~m} \mathrm{~s}^{-1}$ (4\%), other measures of EETC intensity are not significantly affected by anthropogenic GHG forcing (Table 2, Figure 3b-e).

Dynamical downscaling enhances the projected increase in maximum EETC precipitation from $46 \%$ (14 mm day $\left.^{-1}\right)$ to $52 \%$ (20 mm day ${ }^{-1}$ ) (RCMF-DC minus RCMH-DC) (Table 2, Figure 3f). Maximum precipitation 
associated with EETCs increases by $10.6 \%$ per degree warming for the downscaled data (Table 3). As in CanESM2, the projected increase is consistent with a $35 \%$ increase in specific humidity at $850 \mathrm{hPa}$ for October to March (not shown).

To summarize, EETCs simulated by CanESM2 are slightly weaker compared to ERA-Interim. Dynamical downscaling increases maximum EETC precipitation by $22 \%$, which suggests that dynamical downscaling may have enhanced the positive feedback between ETC intensification and latent heat release. Anthropogenic GHG forcing is projected to increase maximum EETC precipitation by $46 \%$ for the global data and by $52 \%$ for the downscaled data. The corresponding precipitation increase per degree warming is $8.9 \% \mathrm{~K}^{-1}$ and $10.6 \% \mathrm{~K}^{-1}$ for CanESM2 and CanRCM4, respectively, which exceeds the Clausius-Clapeyron relation of $6.6 \% \mathrm{~K}^{-1}$.

\subsubsection{Life cycle}

Life cycle composites show that explosive development occurs within a period of two days, with a maximum deepening rate of $24 \mathrm{hPa} 24 \mathrm{~h}^{-1}$ (Figure 5, ERAH-SH). MSLP drops from $1011 \mathrm{hPa}$ to $971 \mathrm{hPa}$, relative vorticity increases from $3.510^{-5} \mathrm{~s}^{-1}$ to $9.910^{-5} \mathrm{~s}^{-1}$, and maximum precipitation increases from $8 \mathrm{~mm} \mathrm{day}^{-1}$ to $25 \mathrm{~mm}$ day $^{-1}$. EETCs reach their minimum MSLP and maximum precipitation values approximately 6 hours after their maximum vorticity. The rate of MSLP intensification is much stronger compared to the rate of MSLP decay. The corresponding rates for relative vorticity and maximum precipitation on the other hand are quite similar. Similar rates are presented in Bengtsson et al. (2009).

CanESM2 reproduces these patterns well, with slightly smaller changes in MSLP (from $1011 \mathrm{hPa}$ to $976 \mathrm{hPa}$ ), relative vorticity (from $3.110^{-5} \mathrm{~s}^{-1}$ to $9.210^{-5} \mathrm{~s}^{-1}$ ), and maximum precipitation (from $7 \mathrm{~mm} \mathrm{day}^{-1}$ to $23 \mathrm{~mm}^{-1}$ day $^{-1}$ ) (Figure 5, GCMH-SH). The timing of the maximum intensities in GCMH-SH is accurate for MSLP and relative vorticity, and 12 hours early for maximum precipitation.

Regridding ERA-Interim to the NAE22 grid prior to tracking (ERAH-DC) leads to similar but not identical life cycle composites compared to ERAH-SH, with MSLP dropping from $1011 \mathrm{hPa}$ to $973 \mathrm{hPa}$, relative vorticity increasing from 2.8 to $9.010^{-5} \mathrm{~s}^{-1}$, and precipitation rising from 6 to $26 \mathrm{~mm}^{\text {day }}{ }^{-1}$. Life cycle composites of GCMHDC are similar to the ones of ERAH-DC for MSLP (from $1012 \mathrm{hPa}$ to $978 \mathrm{hPa}$ ) and maximum precipitation (from $5 \mathrm{~mm} \mathrm{day}^{-1}$ to $25 \mathrm{~mm} \mathrm{day}^{-1}$ ). The increase in maximum relative vorticity however is smaller in GCMH-DC compared to ERAH-DC (from $2.610^{-5} \mathrm{~s}^{-1}$ to $7.710^{-5} \mathrm{~s}^{-1}$ ). Dynamical downscaling slightly improves the result by 
increasing maximum vorticity to $8.310^{-5} \mathrm{~s}^{-1}$ (RCMH-DC). However, the MSLP minimum in RCMH-DC is still too high, and the precipitation maximum is still 12 hours too early compared to ERAH-DC.

Projections under RCP8.5 forcing exhibit no major impacts on the overall life cycle patterns described above. The most noticeable change is the projected increase in maximum precipitation from $23 \mathrm{~mm}^{\mathrm{day}}{ }^{-1}$ in the historical experiment (GCMH-SH) to $34 \mathrm{~mm} \mathrm{day}^{-1}$ under RCP8.5 forcing (GCMF-SH). The corresponding values for the downscaled experiment are slightly higher, with $27 \mathrm{~mm}$ day $^{-1}$ for RCMH-DC and $39 \mathrm{~mm} \mathrm{day}^{-1}$ for RCMF-DC.

To summarize, life cycle composites show that explosive development occurs within a period of two days, where a sharp drop in MSLP by $24 \mathrm{hPa} 24 \mathrm{~h}^{-1}$ coincides with a rise in relative vorticity and maximum precipitation. CanESM2 reproduces these patterns reasonably well, with a tendency for too high MSLP and too low relative vorticity values, and a peak in maximum precipitation that is 12 hours too early. Downscaling CanESM2 slightly improves this result by increasing maximum vorticity. Projections under RCP8.5 forcing exhibit a projected increase in maximum precipitation from $23 \mathrm{~mm} \mathrm{day}^{-1}$ (GCMH-SH) to $34 \mathrm{~mm} \mathrm{day}^{-1}$ (GCMF-SH), with slightly higher values for the corresponding downscaled counterparts.

\subsection{Baroclinic instability}

The highest density of EETC tracks occurs in a region with strong cold season lower tropospheric Eady growth rate $\left(1.8\right.$ to 2.0 day $\left.^{-1}\right)$ (ERAH-SH) (Figure $6 \mathrm{a}$ and b). The highest zonal mean frequency is located at about $45^{\circ}$ north where the zonal mean Eady growth rate is about 1.6 day $^{-1}$ (Figure 7 a and c). This also applies to experiments that are based on discrete cosine transfrom rather than spherical harmonic decomposition (Figure 7b). CanESM2 underestimates the zonal mean Eady growth rate value by 0.1 day $^{-1}$, which is consistent with the negative EETC frequency bias (Figure 6c and Figure 7c). Similar underestimation along North America's Atlantic coast is also found in the multi-model mean of Eady growth rates in the CMIP5 climate model ensemble (Seiler and Zwiers, 2016a; their Figure 101). The impact of dynamical downscaling on the Eady growth rate is not statistically significant in the main region of the storm track (Figure 6d and Figure 7d).

Projections under RCP8.5 forcing show a decrease of the lower tropospheric Eady growth rate by 0.2 day ${ }^{-1}$ between $40^{\circ}$ and $45^{\circ}$ latitude (Figure 6e and Figure 7c), which is consistent with the projected decline in EETC frequency in CanESM2, and with Eady growth rate projections in other CMIP5 models (Seiler and Zwiers, 2016b). Also, the zonal mean maximum Eady growth rate and the maximum EETC frequency are projected to shift northwards by about two to three degrees latitude (Figure 7a and c). Downscaling does not significantly 
impact the projected decrease in the Eady growth rate in most of the storm track region (Figure 6f and Figure 7c and d). This is in contrast to Willison et al. (2015) who showed that the lower tropospheric Eady growth rate increases with anthropogenic GHG forcing, and that this impact is enhanced when increasing the horizontal model resolution in a pseudo global warming experiment.

The low Eady growth rate in CanESM2 is due to underestimation of vertical wind shear rather than overestimation of the Brunt-Väisälä frequency, as CanESM2 slightly underestimates the latter by $0.2510^{-3}$ to $0.510^{-3}$ $\mathrm{s}^{-1}$ (not shown). The Eady growth rate bias coincides with a warm temperature bias in the lower troposphere $(850 \mathrm{hPa})$ over Eastern Canada between $40^{\circ}$ and $60^{\circ}$ latitude $(2-4 \mathrm{~K})$ (Figure $8 \mathrm{a}$ and b, and Figure 9a). The resulting meridional temperature gradients are therefore smaller in CanESM2 compared to ERA-Interim, with differences as large as $0.3 \mathrm{~K}$ per $100 \mathrm{~km}$ at $850 \mathrm{hPa}$ (Figure 8c, yellow shaded area along North America's Atlantic coast). This could lead to underestimation of the Eady growth rate, as vertical wind shear and the meridional temperature gradients are linked through the thermal wind equation.

To summarize, the highest density of EETC tracks occurs in a region with strong cold season lower tropospheric Eady growth rate. CanESM2 underestimates the lower tropospheric Eady growth rate by 0.1 day $^{-1}$, which is consistent with the model's negative EETC frequency bias. Anthropogenic GHG forcing is projected to decrease the lower tropospheric Eady growth rate by 0.2 day $^{-1}$, which may explain the projected decline in EETC frequency in CanESM2. The negative Eady growth rate bias in CanESM2 is due to an underestimation of vertical wind shear rather than an overestimation of the Brunt-Väisälä frequency. The weak vertical wind shear is consistent with too weak meridional temperature gradients related to a warm temperature bias in the lower troposphere over Eastern Canada. Dynamical downscaling has no significant impacts on Eady growth rate biases and projections in most of the storm track region.

\section{Discussion}

This study explores how dynamical downscaling affects model biases and projections of EETCs along North America's Atlantic coast. The regional climate model CanRCM4 is forced with the global climate model CanESM2 for the periods 1981 to 2000 and 2081 to 2100 . ETCs are tracked from relative vorticity using an objective feature tracking algorithm. Special attention is paid to the impact of different spatial filters used for data with different spatial grids. CanESM2 is shown to simulate too many weak and too few strong ETCs, which is consistent with findings from Zappa et al. (2013a). Dynamical downscaling reduces this bias by increasing the number of stronger 
storms, consistent with results from Long et al. (2009). Forcing under the RCP8.5 emission scenario is projected to weaken ETCs when comparing the late 21st century with the late 20th century, leading to more weaker and fewer stronger storms. Downscaling further reduces the projected number of stronger storms. The total number of ETCs, and the frequency of extreme ETCs (99th percentile) are not projected to change statistically significantly.

CanESM2 underestimates EETC track frequency by $38 \%$, which is comparable to the biases of other CMIP5 models (Seiler and Zwiers, 2016a). Dynamical downscaling reduces the CanESM2 bias to -22\%. The relatively higher EETC frequency in CanRCM4 coincides with a corresponding $22 \%$ increase in maximum EETC precipitation. This is consistent with Willison et al. (2013) who show that a positive feedback between ETC intensification and latent heat release is enhanced at higher horizontal model resolution. Dynamical downscaling with CanRCM4 does not completely eliminate the EETC frequency bias of CanESM2, possibly due to underestimation of the Eady growth rate, which is not affected by dynamical downscaling. The use of spectral nudging may have constrained the Eady growth rate in CanRCM4 to that of the driving model.

The negative Eady growth rate bias in CanESM2 is due to underestimation of vertical wind shear rather than overestimation of the Brunt-Väisälä frequency. The weak vertical wind shear may be caused by weak meridional temperature gradients, as both variables are linked through the thermal wind equation. Meridional temperature gradients are smaller in CanESM2 compared to ERA-Interim, possibly due to a warm temperature bias in the lower troposphere over Eastern Canada. We conclude that the coarse spatial resolution of global climate models presents an important limitation for simulating extreme ETCs, but biases in the large scale circulation that affect baroclinic instability may be just as relevant. Future research on model biases of intense coastal storms should assess the mechanisms that lead to an underestimation of the lower-tropospheric Eady growth rate along North America's Atlantic coast.

CanESM2 projects a $15 \%$ decrease in EETC frequency (4 tracks $\mathrm{yr}^{-1}$ ) by the end of this century, which is comparable to CMIP5 model projections (Seiler and Zwiers, 2016b). Dynamical downscaling has little impacts on the relative changes that are projected in EETC track frequency and intensity, suggesting that CMIP5 projections in Seiler and Zwiers (2016b) may not be very sensitive to horizontal model resolution. This is consistent with our finding that dynamical downscaling has no significant impact on the projected reduction in the lower tropospheric Eady growth rate, and consistent with Long et al. (2009) (their Figure 9). In contrast Willison et al. (2015) showed that the lower tropospheric Eady growth rate increases with anthropogenic GHG forcing, and that this impact is enhanced when increasing the horizontal model resolution in a pseudo global warming experiment. Such contrasts 
may arise due to the different nature of pseudo global warming experiments, and may also be related to the fact that our experiments were spectrally nudged. Future research could compare these results to climate model biases and projections of EETCs in HighResMIP simulations. It is possible that such simulations also reduce the negative Eady growth rate bias, as HighResMIP runs are not constrained by spectral nudging.

The projected decline in EETC frequency is consistent with a 0.2 day $^{-1}$ decrease in the lower tropospheric Eady growth rate between $40^{\circ}$ and $45^{\circ}$ latitude. The Eady growth rate bias $\left(-0.1\right.$ day $\left.^{-1}\right)$ is smaller than its projected reduction $\left(-0.2\right.$ day $\left.^{-1}\right)$, but the EETC track frequency bias $(-38 \%)$ is larger than its projected decline $(-15 \%)$. This suggests that the impact of the projected Eady growth rate reduction might be partially offset by a mechanism that favors ETC intensification, such as enhanced baroclinic instability in the upper troposphere related to tropical amplification (Hall et al., 1994), or condensational heating corresponding to the projected increase in maximum EETC precipitation. Changes in the contribution of moist diabatic processes to EETC intensification could be analyzed from the potential vorticity perspective (Davis and Emanuel, 1991).

Maximum EETC precipitation is projected to increase by $46 \%$ in the global model. The projected precipitation rate per degree warming is estimated as $8.9 \% \mathrm{~K}^{-1}$, which exceeds the Clausius-Clapeyron rate of $6.6 \% \mathrm{~K}^{-1}$ for the region, reflecting the role of moisture convergence in maximum EETC precipitation. Changes in the spatial distribution of precipitation could be studied in more detail in storm centered composits (e.g. Bengtsson et al., 2009).

To conclude, this study assesses how dynamical downscaling with a spectrally nudged model affects biases and projections of EETCs along North America's Atlantic coast. Dynamical downscaling significantly reduces EETC biases, likely due to enhanced precipitation and associated condensational heating. The remaining bias is consistent with underestimation of baroclinic instability, which is not affected by dynamical downscaling. Projections under RCP8.5 forcing exhibit a reduction in EETC frequency, and an increase maximum EETCs precipitation. The projected relative changes are not very sensitive to horizontal model resolution. Future research should assess the relative contribution of moist diabatic processes for ETC intensification, and study how these contributions vary with storm intensity under current and projected climatic conditions.

\section{Acknowledgements}

The authors gratefully acknowledge the financial support of the Marine Environmental Observation Prediction and Response Network (MEOPAR) for this research. We thank Dr. Yanjun Jiao from the Canadian Centre for 
Climate Modelling and Analysis (CCCma) for providing us with data from CanRCM4. We acknowledge the

World Climate Research Programme's Working Group on Coupled Modelling, which is responsible for CMIP, and we thank CCCma and ECMWF for producing and making available their model output. For CMIP the U.S. Department of Energy's Program for Climate Model Diagnosis and Intercomparison provides coordinating support and led development of software infrastructure in partnership with the Global Organization for Earth System Science Portals.

\section{References}

Anderson, D., K. I. Hodges, and B. J. Hoskins, 2003: Sensitivity of feature-based analysis methods of storm tracks to the form of background field removal. Monthly weather review, 131 (3), 565-573.

Arora, V. K., and Coauthors, 2011: Carbon emission limits required to satisfy future representative concentration pathways of greenhouse gases. Geophysical Research Letters, 38 (5), n/a-n/a, doi:10.1029/2010GL046270, URL http://dx.doi.org/10.1029/2010GL046270, 105805.

Bengtsson, L., K. I. Hodges, and N. Keenlyside, 2009: Will extratropical storms intensify in a warmer climate? Journal of Climate, 22 (9), 2276-2301.

Bengtsson, L., K. I. Hodges, and E. Roeckner, 2006: Storm tracks and climate change. Journal of Climate, 19 (15), 3518-3543.

Chang, E. K. M., Y. Guo, and X. Xia, 2012: CMIP5 multimodel ensemble projection of storm track change under global warming. Journal of Geophysical Research: Atmospheres, 117 (D23), n/a-n/a, doi:10.1029/ 2012JD018578, URL http://dx.doi.org/10.1029/2012JD018578, d23118.

Christensen, J., and Coauthors, 2013: Climate Phenomena and their Relevance for Future Regional Climate Change. In: Climate Change 2013: The Physical Science Basis. Working Group I Contribution to the Fifth Assessment Report of the Intergovernmental Panel on Climate Change. Tech. rep., Groupe d'experts intergouvernemental sur l'evolution du climat/Intergovernmental Panel on Climate Change-IPCC, C/O World Meteorological Organization, 7bis Avenue de la Paix, CP 2300 CH-1211 Geneva 2 (Switzerland).

Colle, B. A., J. F. Booth, and E. K. Chang, 2015: A Review of Historical and Future Changes of Extratropical Cyclones and Associated Impacts Along the US East Coast. Current Climate Change Reports, 1 (3), $125-143$. Collins, M., and Coauthors, 2013: Long-term Climate Change: Projections, Commitments and Irreversibility. In: Climate Change 2013: The Physical Science Basis. Working Group I Contribution to the Fifth Assessment 
Report of the Intergovernmental Panel on Climate Change. Tech. rep., Groupe d'experts intergouvernemental sur l'evolution du climat/Intergovernmental Panel on Climate Change-IPCC, C/O World Meteorological Organization, 7bis Avenue de la Paix, CP 2300 CH-1211 Geneva 2 (Switzerland).

Côté, H., K. M. Grise, S.-W. Son, R. de Elía, and A. Frigon, 2015: Challenges of tracking extratropical cyclones in regional climate models. Climate Dynamics, 44 (11-12), 3101-3109.

Davis, C. A., and K. A. Emanuel, 1991: Potential vorticity diagnostics of cyclogenesis. Monthly weather review, 119 (8), 1929-1953.

Dee, D., and Coauthors, 2011: The ERA-Interim reanalysis: Configuration and performance of the data assimilation system. Quarterly Journal of the Royal Meteorological Society, 137 (656), 553-597.

Denis, B., J. Côté, and R. Laprise, 2002: Spectral decomposition of two-dimensional atmospheric fields on limitedarea domains using the discrete cosine transform (DCT). Monthly Weather Review, 130 (7), 1812-1829.

Fink, A. H., S. Pohle, J. G. Pinto, and P. Knippertz, 2012: Diagnosing the influence of diabatic processes on the explosive deepening of extratropical cyclones. Geophysical Research Letters, 39 (7), n/a-n/a, doi:10.1029/ 2012GL051025, URL http://dx.doi.org/10.1029/2012GL051025, 107803.

Giorgi, F., C. Jones, G. R. Asrar, and Coauthors, 2009: Addressing climate information needs at the regional level: the CORDEX framework. World Meteorological Organization (WMO) Bulletin, 58 (3), 175.

Hall, N. M., B. J. Hoskins, P. J. Valdes, and C. A. Senior, 1994: Storm tracks in a high-resolution GCM with doubled carbon dioxide. Quarterly Journal of the Royal Meteorological Society, 120 (519), 1209-1230.

Hodges, K., 1994: A general method for tracking analysis and its application to meteorological data. Monthly Weather Review, 122 (11), 2573-2586.

Hodges, K., 1999: Adaptive constraints for feature tracking. Monthly Weather Review, 127 (6), $1362-1373$.

Hodges, K., and Coauthors, 1995: Feature tracking on the unit-sphere. Monthly Weather Review, 123 (12), $3458-3465$.

Hoskins, B. J., and P. J. Valdes, 1990: On the existence of storm-tracks. Journal of the atmospheric sciences, 47 (15), 1854-1864.

Kocin, P. J., P. N. Schumacher, R. F. Morales Jr, and L. W. Uccellini, 1995: Overview of the 12-14 March 1993 superstorm. Bulletin of the American Meteorological Society, 76 (2), 165-182.

Lambert, S. J., and J. C. Fyfe, 2006: Changes in winter cyclone frequencies and strengths simulated in enhanced greenhouse warming experiments: results from the models participating in the IPCC diagnostic exercise. Climate 
Dynamics, 26 (7-8), 713-728.

Long, Z., W. Perrie, J. Gyakum, R. Laprise, and D. Caya, 2009: Scenario changes in the climatology of winter midlatitude cyclone activity over eastern North America and the Northwest Atlantic. Journal of Geophysical Research: Atmospheres, 114 (D12), n/a-n/a, doi:10.1029/2008JD010869, URL http://dx.doi.org/10.1029/ 2008JD010869, d12111.

Marciano, C. G., G. M. Lackmann, and W. A. Robinson, 2015: Changes in US East Coast cyclone dynamics with climate change. Journal of Climate, 28 (2), 468-484.

McDonald, R. E., 2011: Understanding the impact of climate change on Northern Hemisphere extra-tropical cyclones. Climate dynamics, 37 (7-8), 1399-1425.

R Core Team, 2013: R: A Language and Environment for Statistical Computing. Vienna, Austria, R Foundation for Statistical Computing, URL http://www.R-project.org/.

Roebber, P. J., 1984: Statistical analysis and updated climatology of explosive cyclones. Monthly Weather Review, 112 (8), 1577-1589.

Sanders, F., and J. R. Gyakum, 1980: Synoptic-dynamic climatology of the "bomb". Monthly Weather Review, 108 (10), 1589-1606.

Scinocca, J., and Coauthors, 2016: Coordinated global and regional climate modeling*. Journal of Climate, $29(1), 17-35$.

Seiler, C., and F. Zwiers, 2016a: How well do CMIP5 climate models reproduce explosive cyclones in the extratropics of the Northern Hemisphere? Climate Dynamics, 46 (3-4), 1241-1256.

Seiler, C., and F. Zwiers, 2016b: How will climate change affect explosive cyclones in the extratropics of the Northern Hemisphere? Climate Dynamics, 46 (11), 3633-3644.

Stull, R. B., 2000: Meteorology for scientists and engineers: a technical companion book with Ahrens' Meteorology Today. Brooks/Cole.

Taylor, K. E., R. J. Stouffer, and G. A. Meehl, 2012: An overview of CMIP5 and the experiment design. Bulletin of the American Meteorological Society, 93 (4), 485-498.

Ulbrich, U., J. Pinto, H. Kupfer, G. Leckebusch, T. Spangehl, and M. Reyers, 2008: Changing Northern Hemisphere storm tracks in an ensemble of IPCC climate change simulations. Journal of climate, 21 (8), 1669-1679. von Salzen, K., and Coauthors, 2013: The Canadian fourth generation atmospheric global climate model (CanAM4). Part I: representation of physical processes. Atmosphere-Ocean, 51 (1), 104-125. 
Willison, J., W. A. Robinson, and G. M. Lackmann, 2013: The importance of resolving mesoscale latent heating in the North Atlantic storm track. Journal of the Atmospheric Sciences, 70 (7), 2234-2250.

Willison, J., W. A. Robinson, and G. M. Lackmann, 2015: North Atlantic Storm-Track Sensitivity to Warming Increases with Model Resolution. Journal of Climate, 28 (11), 4513-4524.

Zappa, G., L. C. Shaffrey, and K. I. Hodges, 2013a: The Ability of CMIP5 Models to Simulate North Atlantic Extratropical Cyclones*. Journal of Climate, 26 (15), 5379-5396.

Zappa, G., L. C. Shaffrey, K. I. Hodges, P. G. Sansom, and D. B. Stephenson, 2013b: A multimodel assessment of future projections of north atlantic and european extratropical cyclones in the cmip 5 climate models*. Journal of Climate, 26 (16), 5846-5862. 


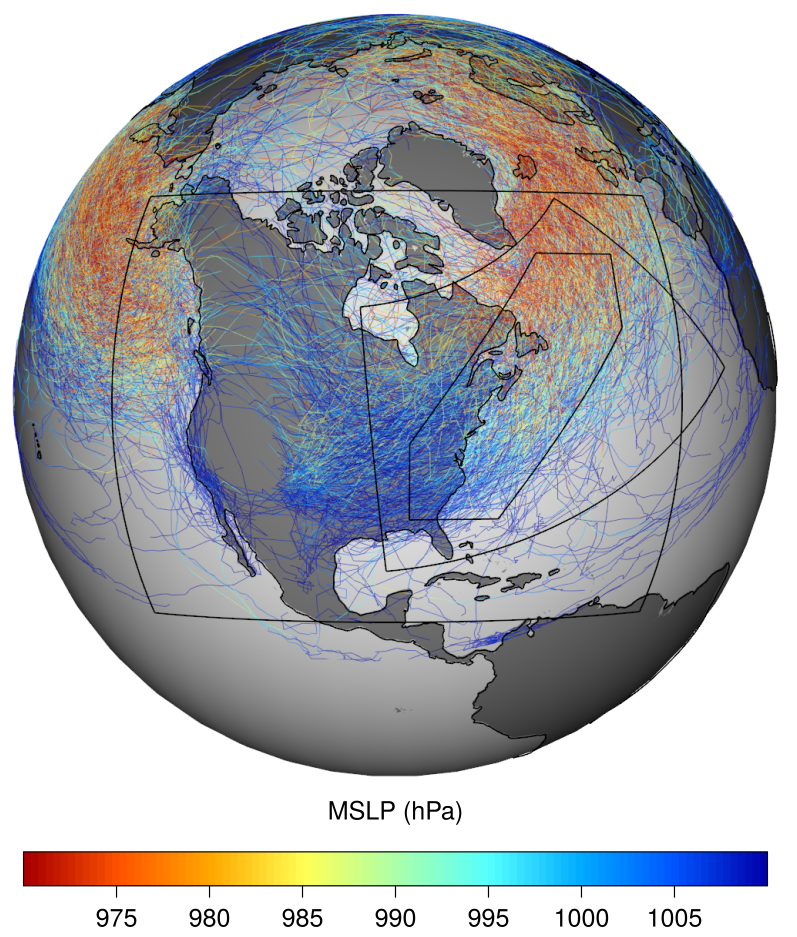

Fig. 1 EETC tracks and their along track MSLP values computed from ERA-Interim for the period 1981-2000. The outer polygon presents the CanRCM4 eastward extended North American model domain, the small polygon shows the area that is used to compute statistics for coastal storms, and the middle-sized polygon encloses the area used to compute zonal mean values in Figure 7. 


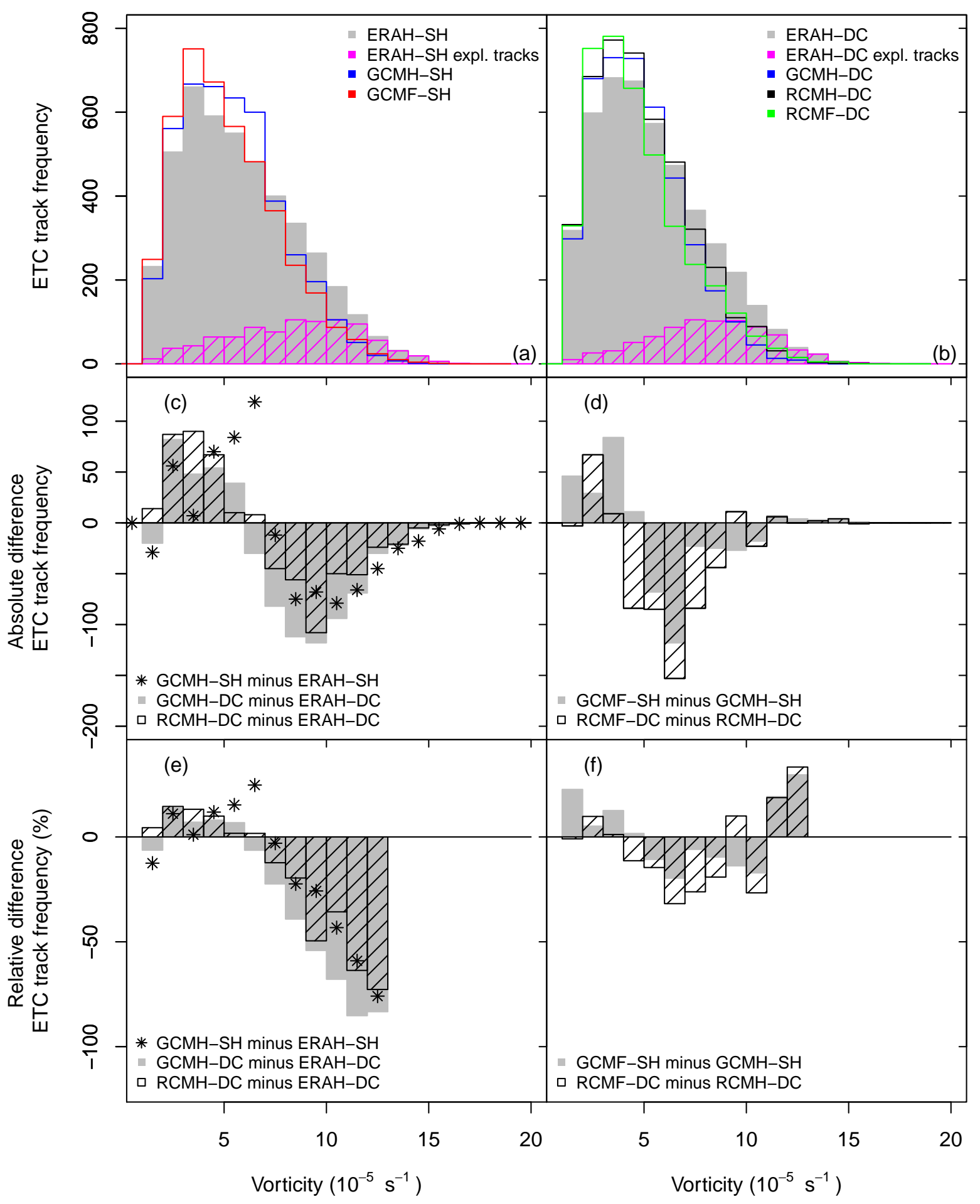

Fig. 2 Frequency histograms of the maximum relative vorticity that is attained in each ETC track along North America's Atlantic coast for data on (a) the global grid and (b) the NAE22 grid. Subplots (c) and (d) show the absolute biases and the projected changes, and subplots (e) and (f) show the relative biases and the projected changes, respectively. The relative biases are shown for relative vorticity values below $1310^{-5} \mathrm{~s}^{-1}$ due to the small number of ETC tracks at higher intensities. Only ETC segments that are enclosed by the polygon that encompasses North America's Atlantic coast in Figure 1 are considered. 


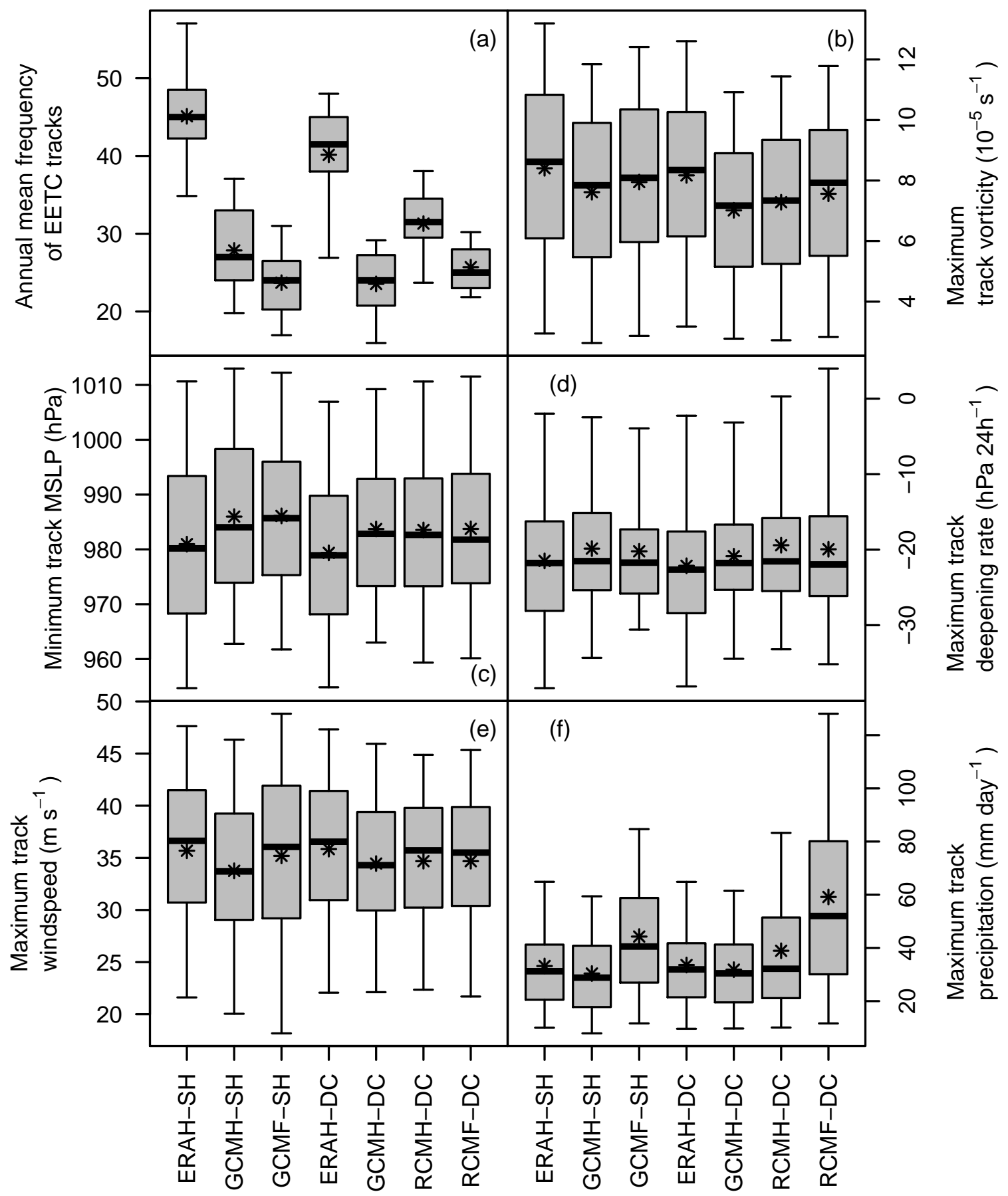

Fig. 3 Percentiles $(0.05,0.25,0.50,0.75,0.95)$ (boxplots) and mean values (asterisks) of (a) annual mean frequency, (b) maximum relative vorticity, (c) minimum MSLP, (d) maximum deepening rate, (e) maximum wind speed, and (f) maximum precipitation of EETC tracks along North America's Atlantic coast. Only EETC segments that are enclosed by the polygon that encompasses North America's Atlantic coast in Figure 1 are considered. 
(a) ERAH-DC

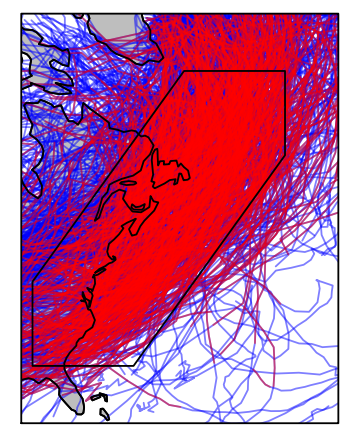

(d) ERAH-DC

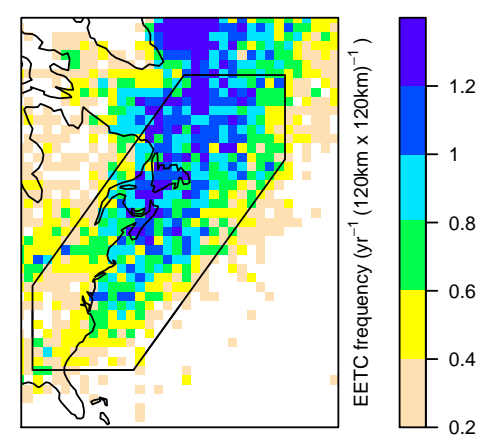

(b) GCMH-DC

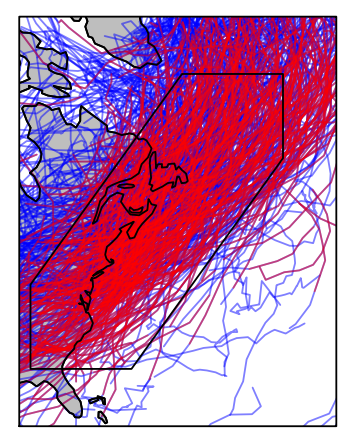

(e) GCMH-DC

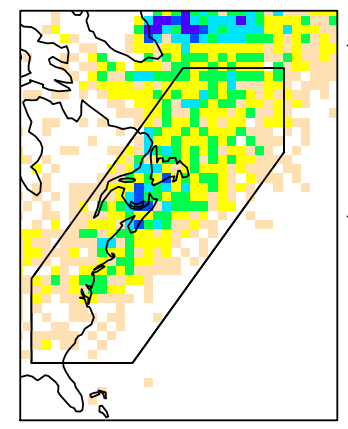

(c) $\mathrm{RCMH}-\mathrm{DC}$

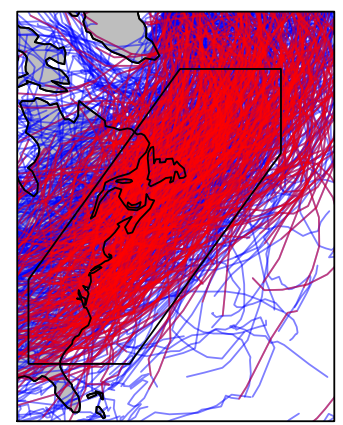

(f) $\mathrm{RCMH}-\mathrm{DC}$

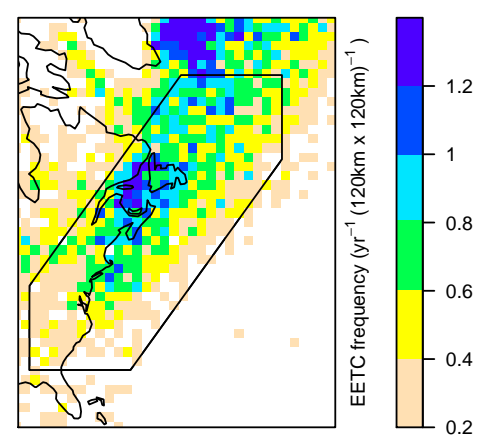

Fig. 4 EETC tracks with explosive segments shaded in red for (a) ERAH-DC, (b) GCMH-DC, and (c) RCMH-DC for the period 1981 to 2000. Subplots (d) to (f) show the corresponding annual frequency of 6 hourly EETC centers. 


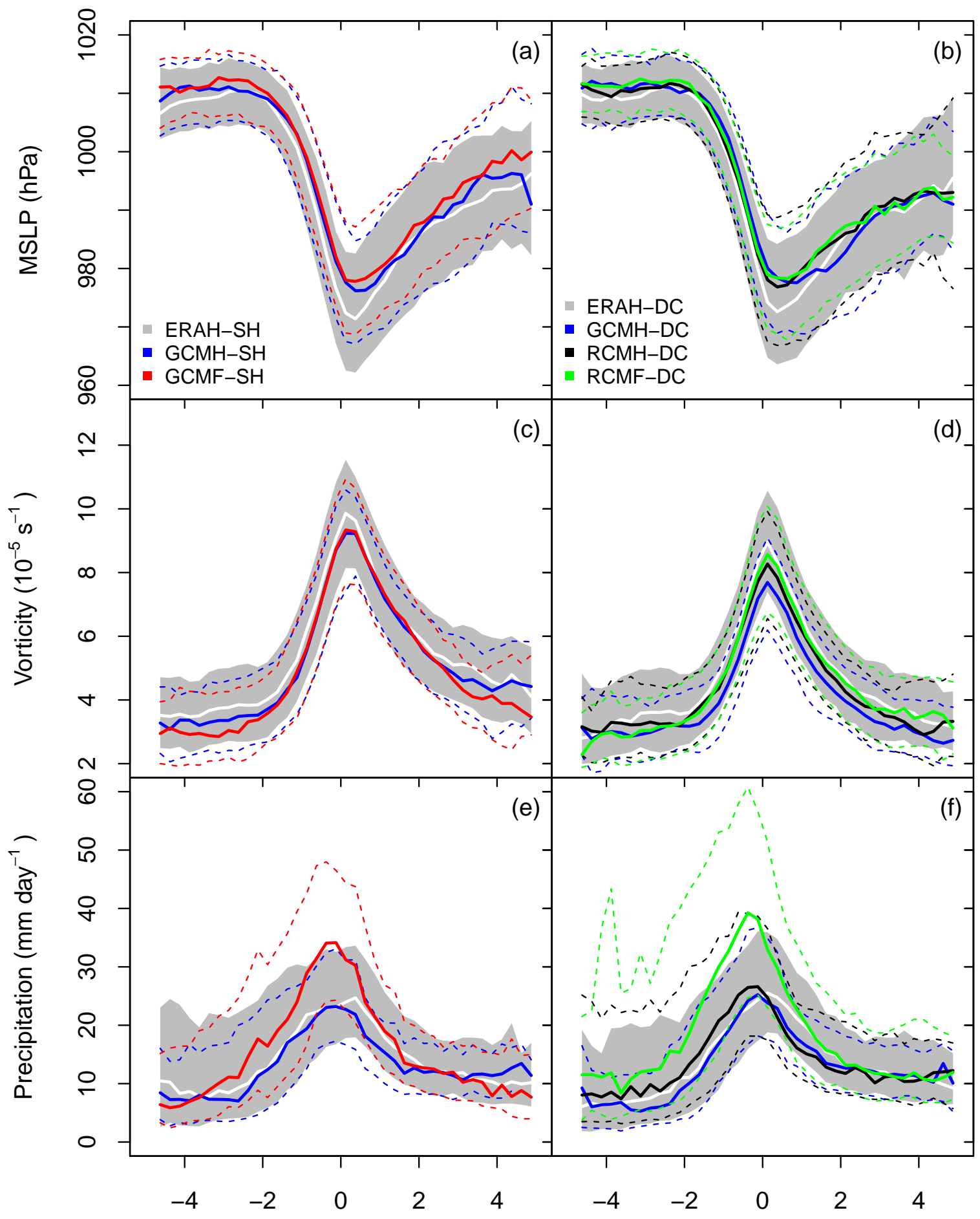

Days from instant of max. vorticity

Days from instant of max. vorticity

Fig. 5 Life cycle composites of all EETCs that pass through the polygon that encompasses North America's Atlantic coast in Figure 1. Contrary to Figure 3, this also includes the parts of EETCs that lie outside the polygon. Parameters shown are (a, b) MSLP, (c, d) relative vorticity, and (e, f) maximum precipitation. Subplots (a, c, and e) and (b, d, and f) show results for experiments that are based on spherical harmonic decomposition and discrete cosine transfrom, respectively. The centered lines show the medians and the outer lines enclose the interquartile ranges. The life cycles of EETC tracks are combined by centering the tracks according to the time step of maximum relative vorticity. 
(a) ERAH-SH
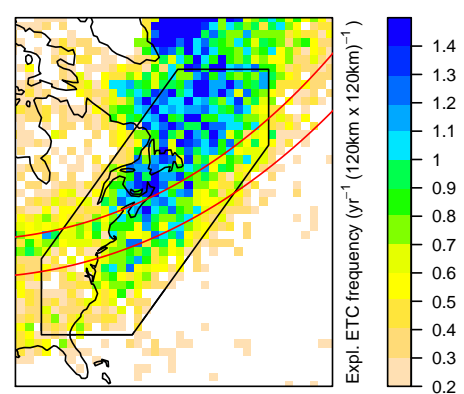

(d) CanRCM4 minus CanESM2 (hist)

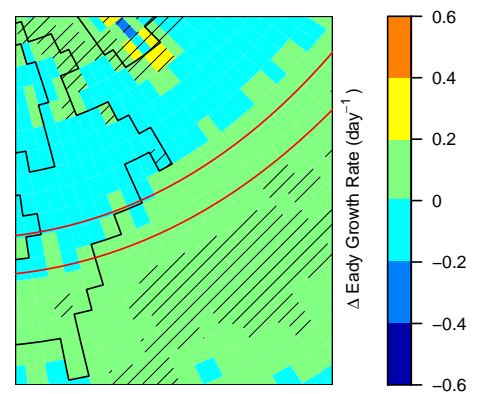

(b) ERA-Int

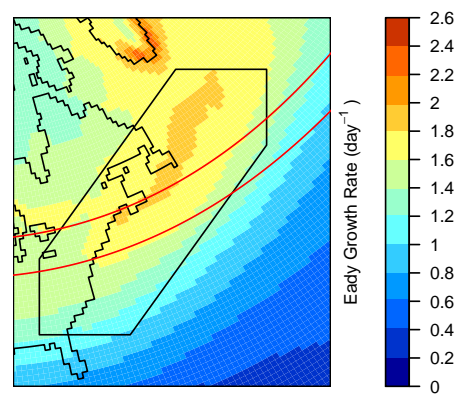

(e) CanESM2 RCP8.5 minus hist

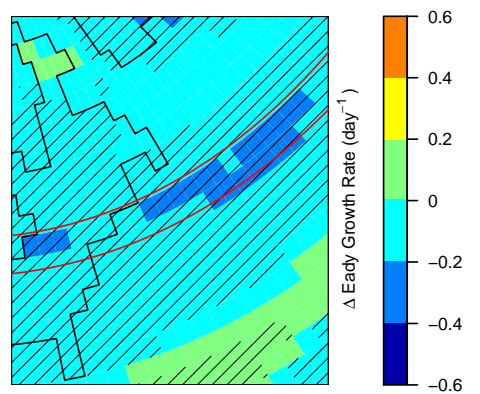

(c) CanESM2 minus ERA-Int (hist)

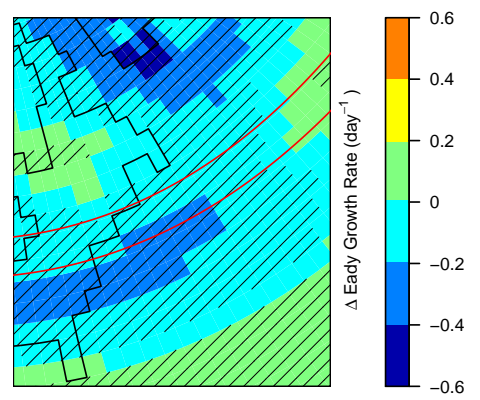

(f) CanRCM4 minus CanESM2 (RCP8.5)

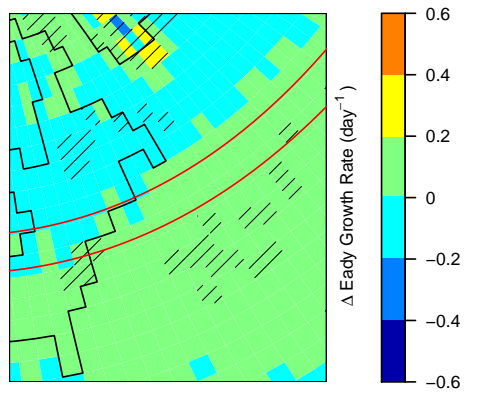

Fig. 6 (a) EETC frequency in ERA-Interim (ERA-SH) for the period 1981 to 2000, (b) lower tropospheric Eady growth rate of ERA-Interim for the same period during the cold season, (c) Eady growth rate bias of CanESM2 (1981-2000), (d) the difference between Eady growth rate in CanESM2 and CanRCM4 (1981-2000), (e) Eady growth rate projections under RCP8.5 by CanESM2 (1981-2000 and 2081-2100), and (f) the difference between Eady growth rate projections from CanESM2 and CanRCM4 (2081-2100). Regions with statistically significant differences at the $5 \%$ level are hatched (Wilcox test, $\mathrm{R}$ Core Team, 2013). The red lines represent $40^{\circ}$ and $45^{\circ}$ of northern latitude. 


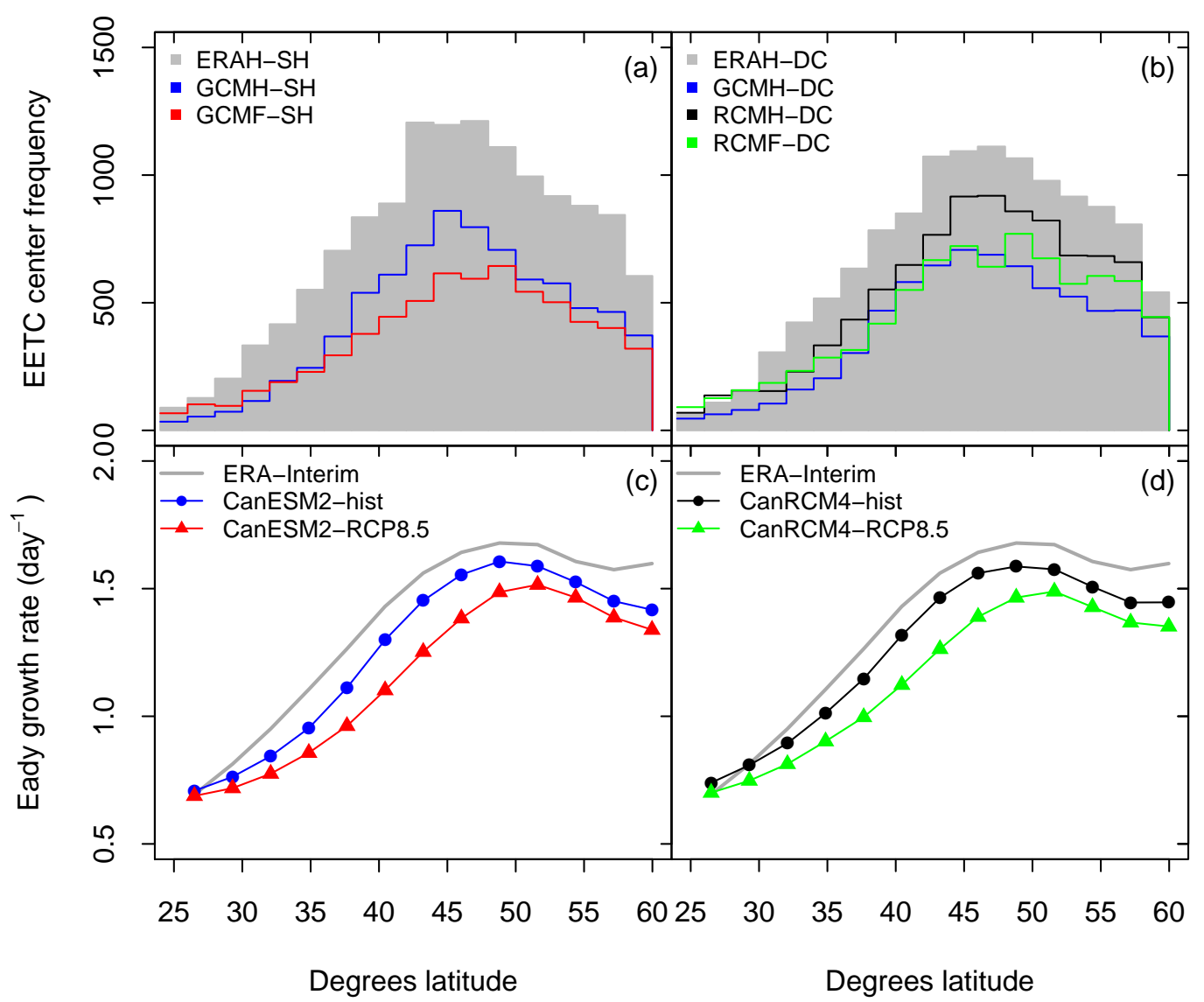

Fig. 7 Zonal mean frequency of EETC centers for experiments based on the (a) spherical harmonic decomposition and (b) discrete cosine transform. Subplots (c) and (d) show the corresponding zonal mean Eady growth rates. Zonal means are computed from $25^{\circ}$ to $60^{\circ}$ latitude and from $-90^{\circ}$ to $-25^{\circ}$ longitude, corresponding to the area enclosed by the middle-sized polygon shown in Figure 1. 
(a) Air Temperature Bias at $850 \mathrm{hPa}$

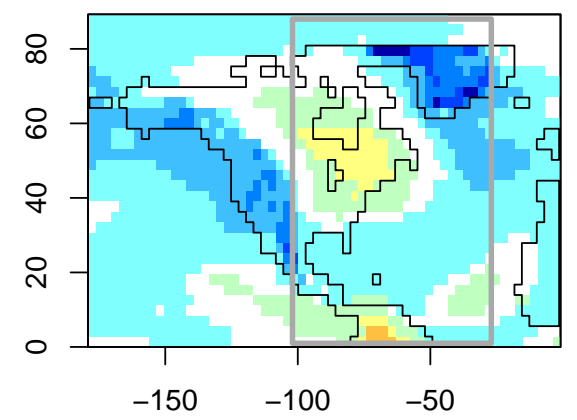

(c) $(\Delta \mathrm{T}) /(\Delta \mathrm{y})$ Bias at $850 \mathrm{hPa}$

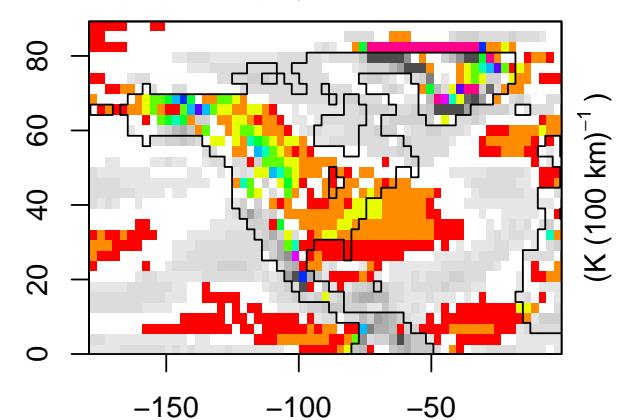

(b) Air Temperature Bias at $500 \mathrm{hPa}$
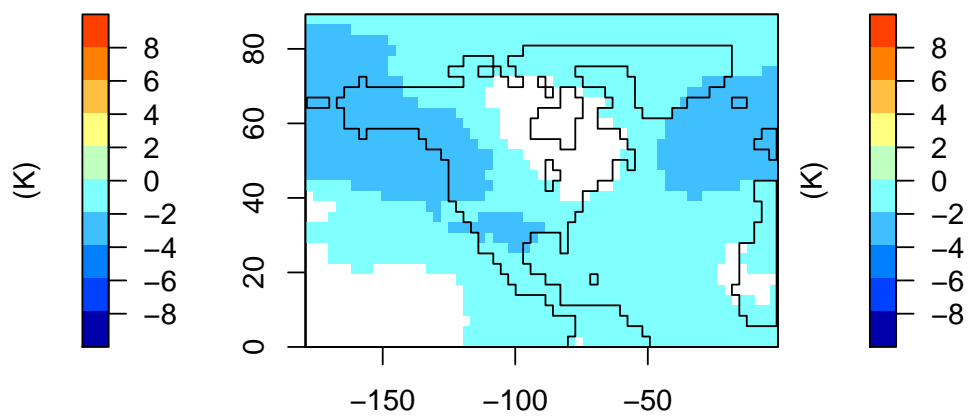

(d) $(\Delta \mathrm{T}) /(\Delta \mathrm{y})$ Bias at $500 \mathrm{hPa}$
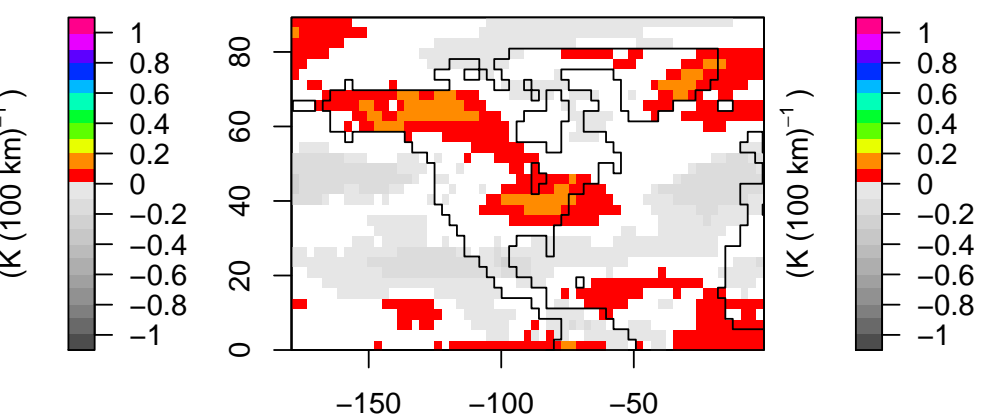

Fig. 8 Air temperature biases at (a) $850 \mathrm{hPa}$ and (b) $500 \mathrm{hPa}$ (CanESM2 minus ERA-Interim) from October to March for the historical period 1981-2000. Subplots (c) and (d) show the corresponding meridional temperature gradient biases. Regions with statistically insignificant differences at the $5 \%$ level are masked out in white (Wilcox test, R Core Team, 2013).

The gray box in (a) shows the region that is used to compute zonal mean values in Figure 9. 

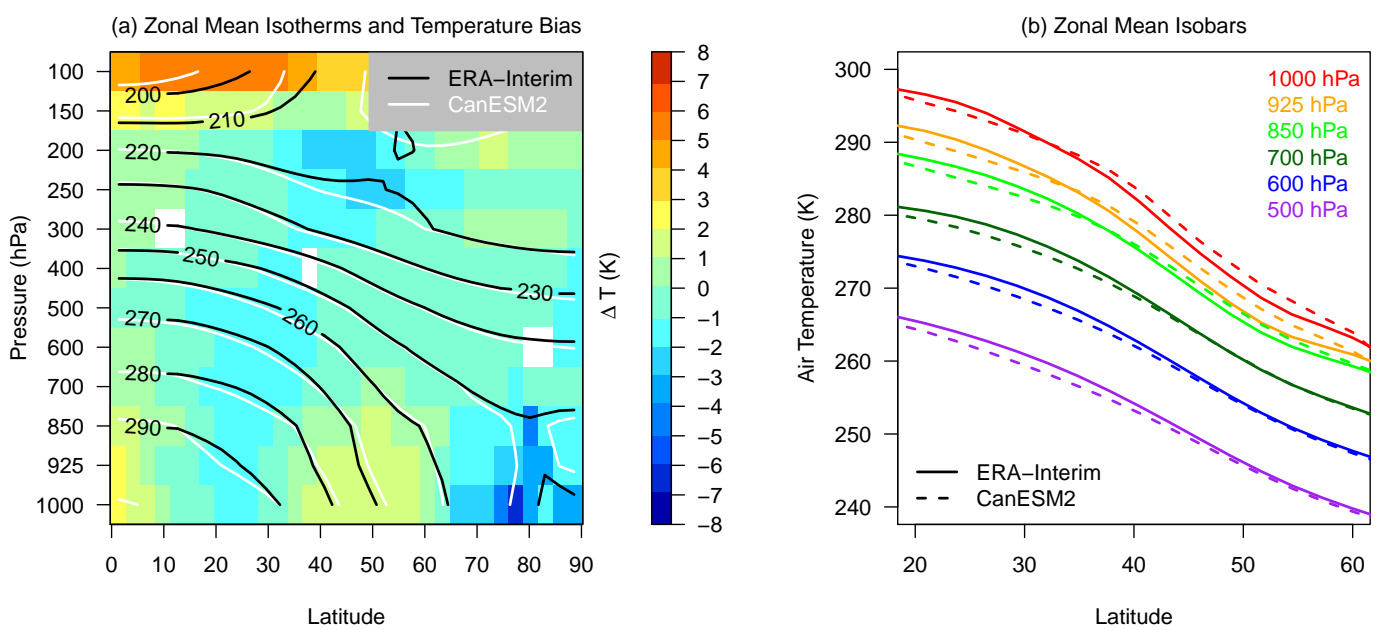

Fig. 9 (a) Zonal mean isotherms and air temperature biases (CanESM2 minus ERA-Interim), and (b) the corresponding temperatures of isobars for selected pressure levels. Zonal means are computed from 1981 to 2000 for the months October to March for a region enclosed by the longitudes $-102^{\circ}$ to $-30^{\circ}$ as denoted by the gray polygon in Figure 8 a. Regions with statistically insignificant differences at the $5 \%$ level are masked out in white in subplot (a) (Wilcox test, R Core Team, 2013). 
Table 1 Experiment ID's, input data, climate model experiments, grids, and spatial filtering techniques. Final grid refers to the grid that is used as input data for TRACK. All data is spatially filtered to T42 or T42 equivalent.

\begin{tabular}{|c|c|c|c|c|c|c|c|}
\hline \multirow[t]{2}{*}{ ID } & \multirow[t]{2}{*}{ Data } & \multirow[t]{2}{*}{ Experiment } & \multicolumn{2}{|c|}{ Native Grid } & \multicolumn{2}{|c|}{ Final Grid } & \multirow{2}{*}{$\begin{array}{l}\text { Spatial filter } \\
\text { (T42 or equivalent) }\end{array}$} \\
\hline & & & Resolution & Extent & Resolution & Extent & \\
\hline ERAH-SH & ERA-Interim & historical & $0.75^{\circ}$ & global & $0.75^{\circ}$ & global & spherical harmonic decomposition \\
\hline GCMH-SH & CanESM2 & historical & $2.8125^{\circ}$ & global & $2.8125^{\circ}$ & global & spherical harmonic decomposition \\
\hline GCMF-SH & CanESM2 & $\mathrm{RCP} 8.5$ & $2.8125^{\circ}$ & global & $2.8125^{\circ}$ & global & spherical harmonic decomposition \\
\hline ERAH-DC & ERA-Interim & historical & $0.75^{\circ}$ & global & $0.22^{\circ}$ & NAE22 & discrete cosine transform \\
\hline GCMH-DC & CanESM2 & historical & $2.8125^{\circ}$ & global & $0.22^{\circ}$ & NAE22 & discrete cosine transform \\
\hline RCMH-DC & CanRCM4[CanESM2] & historical & $0.22^{\circ}$ & NAE22 & $0.22^{\circ}$ & NAE22 & discrete cosine transform \\
\hline RCMF-DC & CanRCM4[CanESM2] & RCP8.5 & $0.22^{\circ}$ & NAE22 & $0.22^{\circ}$ & NAE22 & discrete cosine transform \\
\hline
\end{tabular}


Table 2 Differences in the frequency and intensity of EETC tracks in proximity of North America's Atlantic coast for selected experiments. Intensities (i.e. relative vorticity, MSLP, deepening rate, wind speed, and precipitation) refer to the strongest intensities that are reached on average by EETC tracks. Only EETC segments that are enclosed by the polygon that encompasses North America's Atlantic coast in Figure 1 are considered. Statistically significant differences are written in bold (two-sampled Wilcoxon test, $5 \%$ level).

\begin{tabular}{|c|c|c|c|c|c|c|c|c|c|c|c|c|}
\hline Experiments & \multicolumn{2}{|c|}{ Track freq. } & \multicolumn{2}{|c|}{ Vorticity } & \multicolumn{2}{|c|}{ MSLP } & \multicolumn{2}{|c|}{$\Delta$ MSLP } & \multicolumn{2}{|c|}{ Windspeed } & \multicolumn{2}{|c|}{ Precipitation } \\
\hline GCMH-SH minus ERAH-SH & -17 & -38 & -0.8 & -9.4 & 5.0 & 0.5 & 1.6 & -7.6 & -1.9 & -5.4 & -2.8 & -8.5 \\
\hline GCMH-DC minus ERAH-DC & -17 & -41 & -1.2 & -14.1 & 4.4 & 0.4 & 1.3 & -5.7 & -1.4 & -3.9 & -1.7 & -5.2 \\
\hline RCMH-DC minus GCMH-DC & 8 & 33 & 0.3 & 3.8 & -0.2 & 0.0 & 1.5 & -7.0 & 0.2 & 0.7 & 7.1 & 22.3 \\
\hline GCMF-SH minus GCMH-SH & -4 & -15 & 0.3 & 4.4 & 0.1 & 0.0 & -0.4 & 1.8 & 1.4 & 4.2 & 13.9 & 45.7 \\
\hline RCMF-DC minus RCMH-DC & -6 & -18 & 0.3 & 3.8 & 0.2 & 0.0 & -0.5 & 2.8 & 0.0 & 0.0 & 20.2 & 52.0 \\
\hline
\end{tabular}


Table 3 Projected changes in near-surface air temperature $(\Delta T)$, and saturated vapor pressure $\left(\Delta e_{s}\right)$ averaged over the area enclosed by the small polygon in Figure 1, and maximum EETC precipitation $(\Delta P)$, and the corresponding rates of change per degree warming for CanESM2 and CanRCM4.

\begin{tabular}{cccccc}
\hline & $\Delta T(K)$ & $\Delta e_{s}(\%)$ & $\Delta P(\%)$ & $\frac{\Delta e_{s}}{\Delta T}\left(\frac{\%}{K}\right)$ & $\frac{\Delta P}{\Delta T}\left(\frac{\%}{K}\right)$ \\
\hline CanESM2 & 5.2 & 34.3 & 45.3 & 6.6 & 8.9 \\
CanRCM4 & 4.9 & 32.5 & 54.6 & 6.7 & 10.6 \\
\hline
\end{tabular}

